\title{
An in vitro study of different material properties of Biodentine compared to ProRoot MTA
}

\author{
Markus Kaup ${ }^{1}$ Edgar Schäfer ${ }^{2}$ and Till Dammaschke ${ }^{1 *}$
}

\begin{abstract}
Introduction: The aim of this study was to compare solubility, microhardness, radiopacity, and setting time of Biodentine with ProRoot MTA.

Methods: Solubility in distilled water, radioopacity, and setting time were evaluated in accordance with International Standard ISO 6876:2001. In addition, the solubility in Phosphate Buffered Saline (PBS) buffer was determined. For microhardness-testing, ten samples of each cement were produced. All samples were loaded with a diamond indenter point with a weight of $100 \mathrm{~g}$ for $30 \mathrm{~s}$.

All data were analysed using the Student-t-test.

Results: Both materials fulfilled the requirements of the International Standard ISO 6876:2001 and showed a solubility of $<3 \%$ after $24 \mathrm{~h}$. At all exposure times Biodentine was significantly more soluble than ProRoot MTA $(p<0.0001)$. After immersion in PBS-buffer a precipitation of hydroxyapatite was visible.

The Vickers microhardness for Biodentine was significantly higher $(62.35 \pm 11.55 \mathrm{HV})$ compared with ProRoot MTA $(26.93 \pm 4.66 \mathrm{HV})(p<0.0001)$.

ProRoot MTA was significantly more radiopaque $(6.40 \pm 0.06 \mathrm{~mm} \mathrm{Al})$ than Biodentine $(1.50 \pm 0.10 \mathrm{~mm} \mathrm{Al})(p<0.0001)$.

The setting time for Biodentine ( $85.66 \pm 6.03 \mathrm{~min})$ was significantly lower than for ProRoot MTA (228.33 $\pm 2.88 \mathrm{~min})$ $(p<0.0001)$.

Conclusions: Biodentine and ProRoot MTA displayed different material properties. The solubility of both cements was in accordance with the International Standard ISO 6876:2001, whereas ProRoot MTA showed a significantly lower solubility. With regard to microhardness, Biodentine may be used to replace dentine. The radioopacity of Biodentine did not fulfil the requirements laid down in the International Standard ISO 6876:2001. The setting time for ProRoot MTA is significantly higher. Both materials can be used in different indications where specific material properties may be favourable. Hence, the here tested material properties are of clinical relevance.
\end{abstract}

Keywords: Biodentine, Radiopacity, Setting time, Solubility, Vickers microhardness

\section{Introduction}

Mineral Trioxide Aggregate (MTA; Pro Root MTA, Dentsply Tulsa Dental, Tulsa, OK, USA) is a cement which contains different oxide compounds (sodium- and potassium oxides, calcium oxide, silicon oxide, ferric oxide, aluminium oxide and magnesium oxide) and was introduced in dentistry by Torabinejad and White in the mid 1990s. MTA can be denoted as calcium silicate cement, because its composition is similar to a refined Portland

\footnotetext{
* Correspondence: tillda@uni-muenster.de

${ }^{1}$ Department of Operative Dentistry, Westphalian Wilhelms-University, Albert-Schweitzer-Campus 1, building W 30, 48149 Münster, Germany
} Full list of author information is available at the end of the article cement, which is available in most hardware stores, mixed with bismuth for radioopacity (Table 1) $[1,2]$.

In order to set, it must first be mixed with water. If set MTA gets in contact with tissue fluids, its calcium oxide converts into calcium hydroxide $\left(\mathrm{Ca}(\mathrm{OH})_{2}\right)$. The $\mathrm{Ca}(\mathrm{OH})_{2}$-molecule dissociates into calcium and hydroxyl ions, thereby increasing the $\mathrm{pH}$ value to approximately 12.5 and resulting in the release of calcium ions [3-5]. MTA can be used as endodontic reparation cement for root-end fillings, apical plug formation, closure of radicular perforations and for direct pulp capping according to the manufacturer's product information (Dentsply Tulsa Dental, Tulsa, OK, USA). Since its introduction 
Table 1 Main composition of ProRoot MTA (Dentsply Tulsa Dental, Tulsa, OK, USA) according to [63]

\begin{tabular}{ll}
\hline Powder & Percentage \\
\hline tricalcium silicate $(\mathrm{CaO})_{3} \cdot \mathrm{SiO}_{2}$ & $75 \mathrm{wt} \%$ \\
dicalcium silicate $(\mathrm{CaO})_{2} \cdot \mathrm{SiO}_{2}$ & \\
tricalcium aluminate $(\mathrm{CaO})_{3} \cdot \mathrm{Al}_{2} \mathrm{O}_{3}$ & $20 \mathrm{wt} \%$ \\
bismuth oxide $\mathrm{Bi}_{2} \mathrm{O}_{3}$ & 5 wt $\%$ \\
gypsum $\mathrm{CaSO}_{4} \cdot 2 \mathrm{H}_{2} \mathrm{O}$ & Percentage \\
\hline Liquid & $100 \%$ \\
\hline
\end{tabular}

into the market, the material was examined in several studies and is meanwhile well accepted and widely used for this purpose in dentistry (for review see [6-8]).

Even though ProRoot MTA appears to be the preferred material in the above mentioned indications with many positive features, the cement does have several drawbacks: the handling can be difficult, the setting time is long, the use in the visible crown area may lead to tooth discoloration, the compressive and flexural strength is lower than dentine (therefore it should not be used as a restorative base), and it is quite expensive [9-13].

Recently, a new bioactive calcium silicate cement, Biodentine (Septodont, St. Maur-des-Fossés, France), was launched on the dental market denoted as a dentine substitute. Biodentine consists of a powder in a capsule and liquid in a pipette. The powder mainly contains tricalcium and dicalcium silicate, the principal component of Portland cement and MTA, as well as calcium carbonate. Zirconium dioxide serves as contrast medium. The liquid consists of calcium chloride in an aqueous solution with an admixture of polycarboxylate (Table 2). The powder is mixed with the liquid in a capsule in a triturator for 30 seconds. During the setting of the cement calcium hydroxide is formed. The consistency of Biodentine reminds of that of phosphate cement. Comparable to

Table 2 Composition of Biodentine (Septodont, St. Maur-des-Fossés, France) according to manufacturer's specification

\begin{tabular}{ll}
\hline Powder & Purpose \\
\hline tricalcium silicate $\mathrm{Ca}_{3} \mathrm{SiO}_{5}(>70 \%)$ & main core material \\
dicalcium silicate $\mathrm{Ca}_{2} \mathrm{SiO}_{4}(<15 \%)$ & second core material \\
zirconium oxide $\mathrm{ZrO}_{2}(5 \%)$ & radio-opacifier \\
calcium carbonate $\mathrm{CaCO}_{3}(>10 \%)$ & filler \\
iron oxides $(<1 \%)$ & shade \\
\hline Liquid & Purpose \\
\hline water $\mathrm{H}_{2} \mathrm{O}$ & main liquid \\
calcium chloride $\mathrm{CaCl}_{2}(>15 \%)$ & accelerator \\
hydrosoluble polymer (polycarboxylate) & water reducing agent \\
\hline
\end{tabular}

MTA Biodentine can be used for the treatment of root perforations or of the pulp floor, internal and external resorption, apical plug formation, root-end filling, pulp capping and pulpotomy, but also for temporary sealing of cavities, and cervical fillings [12,14]. In comparison to ProRoot MTA until now considerably less research about Biodentine is available. Thus, the aim of the present study was to examine different physicochemical properties (solubility, Vickers microhardness, radioopacity, and setting time) of Biodentine in comparison with ProRoot MTA.

Solubility is an important factor in assessing the suitability of materials to be used as restorative materials in dentistry. Lack of solubility is a desired characteristic for root repair cements [15] because endodontic and restorative materials should provide a long-term seal and avoid leakage from the oral cavity and/or the periapical tissue. Consequently, a low solubility in distilled water as proposed in the Standard of the International Standard Organisation (ISO) 6876:2001 [16] is required. From other studies it is known that calcium silicate cements have the ability to form hydroxyapatite crystals on their surface after contact with phosphate containing body fluid [17-19]. But until now, it is unclear in how far these crystals formations may have an influence on the solubility. Thus, the solubility testing was performed in distilled water as well as in phosphate containing Phosphate Buffered Saline (PBS) buffer.

Vickers microhardness (HV) can be defined as the resistance to plastic deformation of the surface of a material after indentation or penetration. The reported microhardness values for sound dentine are in the range of 60-90 HV [20-22]. It would be optimal if the surface hardness of a calcium silicate cement could reach the same range as dentine.

Root-end filling and endodontic repair materials must be radiopaque in order to be able to evaluate the quality of the filling. It is known that the radiopacity of a $1 \mathrm{~mm}$ thick dentine layer is equivalent to that of $1 \mathrm{~mm}$ of aluminium [23,24]. Therefore, according to ISO 6876:2001 [16], a radiopacity of $3 \mathrm{~mm}$ of aluminium is requested for root canal filling materials. Materials with a radioopacity value lower than $3 \mathrm{~mm} \mathrm{Al}$ are hardly to distinguish from dentine [25]. Hence, ISO 6876:2001 require a minimal radioopacity equivalent of $3 \mathrm{~mm}$ thick aluminium [16].

The presence of moisture is usually required for calcium silicate cements to set [26]. A short setting time is helpful to facilitate a tight seal between e.g. the root canal system and the periodontium, while a long setting time may result in difficulties with maintaining consistency of the mixture [27].

The null hypothesis of this study was that all tested material properties of Biodentine are comparable to ProRoot MTA. 


\section{Methods}

\section{Solubility test}

With Biodentine and White ProRoot MTA two endodontic cements indicated for the same purpose were included in this study. Biodentine was obtained from Septodont (St. Maur-des-Fossés, France, LOT 48059) and White ProRoot MTA from Dentsply Maillefer (Ballaigues, Switzerland, LOT 10003596).

The solubility tests followed the methodology laid down in ISO 6876:2001 [16] and were determined of immersion of the samples in double-distilled water. In addition, the solubility was determined in PBS buffer, pH 7.4 (AppliChem, Darmstadt, Germany). The specimens' change in weight was recorded. For all sample preparation stainless steel ring moulds having a height of $1.6 \mathrm{~mm}( \pm 0.1 \mathrm{~mm})$ and an internal diameter of $20.0 \mathrm{~mm}( \pm 0.1 \mathrm{~mm})$ were used. All moulds were cleaned in an ultrasound bath with acetone for $15 \mathrm{~min}$. Thereafter a copper wire was fixed at each mould in order to hang the specimens in a glass dish in such way that the surfaces did not touch and the materials remained undisturbed in the dish. Prior to use all moulds were weighed three times (accuracy $\pm 0.0001 \mathrm{~g}$ ) and the mean was calculated.

Both tested materials Biodentine and White ProRoot MTA were mixed according to the manufacturers instructions. The ring moulds were placed on a glass plate and filled to slight excess with the mixed material avoiding air entrapment. All samples were left to set in an incubator (Wärme- und Trockenschrank, Heraeus, Hanau, Germany) at $37^{\circ} \mathrm{C}$ and $95 \%$ relative humidity on a grating for $24 \mathrm{~h}$. Using silicone carbide paper (600 grit) excess material was then trimmed to level the surface of the mould. From each material, 72 samples were prepared for immersion in water and 72 samples for immersion in PBS buffer. In each case the 72 samples were divided into six groups of 12, for immersion in water or in PBS buffer for $1 \mathrm{~min}, 10 \mathrm{~min}, 1 \mathrm{~h}, 24 \mathrm{~h}, 72 \mathrm{~h}$, and $28 \mathrm{~d}$.

Both materials in their ring moulds were weighed (Sartorius type 1801 MPS, Göttingen, Germany) three times prior to the immersion of the samples. The average reading was recorded. All weight measurements were in grams and recorded to four decimal places.

The samples of each material in its ring mould were immersed in a fresh $160 \mathrm{~mL}$ aliquot of liquid at $37^{\circ} \mathrm{C}$ $\left( \pm 1^{\circ} \mathrm{C}\right)$ a time for one day and subsequently in fresh $160 \mathrm{~mL}$ aliquots at weekly intervals. The specimens were placed in an airtight dish $(7 \times 10.5 \times 8 \mathrm{~cm})$ with $95 \%$ $100 \%$ relative humidity such that both surfaces of each sample were freely accessible to the liquid. There was no agitation of the dish. As controls, 24 empty sample moulds together with the copper wire were immersed in distilled water or PBS buffer, respectively, for 28 days, and any changes in weight were recorded.
After the specified immersion period samples of the two cements were removed from the dish using a pair of tweezers, touching only the metal mould. Samples were washed with $3 \mathrm{~mL}$ of double-distilled water and allowed to dry at $37^{\circ} \mathrm{C}$ in an incubator for $24 \mathrm{~h}$. The specimens were placed on a grating in such way that only the metal moulds touched the grating. Thereafter the samples were weighed three times and the mass of the cements was determined to the nearest $0.0001 \mathrm{~g}$. The difference between the original weight of material and its final weight was recorded to the nearest $0.0001 \mathrm{~g}$. This difference in mass was calculated as a percentage of the original weight of the material, recorded to the nearest $0.001 \%$.

\section{Vickers microhardness}

For measurements of Vickers microhardness (HV), Biodentine and ProRoot MTA were mixed according to the manufacturers' instructions. Both mixed cements were brought into silicon moulds with a size of $10 \mathrm{~mm}$ in length, $5 \mathrm{~mm}$ in width and $5 \mathrm{~mm}$ in height. The cements were vibrated for $1 \mathrm{~min}$ with a vibration intensity of $6000 \mathrm{~min}^{-1}$ (KV 36, Wassermann Dental-Maschinen, Hamburg, Germany) to avoid the inclusion of air. Subsequently, the samples were covered with parafilm ("M"Laboratory Film, American CAN Company, Greenwich, CT, USA) and left to set in an incubator at $37^{\circ} \mathrm{C}$ and $95 \%$ relative humidity for $24 \mathrm{~h}$. Ten samples of each cement were produced. One side of the specimens was then trimmed using silicone carbide paper (600 grit).

For the measurement of the microhardness one polished cement surface of each sample was loaded with a diamond indenter point (Durimet, Wetzlar, Germany) with a weight of $100 \mathrm{~g}$ for $30 \mathrm{~s}$ to produce a stamp mark in a homogeneous region of the cement surface. The diamond indenter produced one impression with two orthogonal diagonals equal in length which were measured immediately after discharge. The microhardness was calculated as following:

$$
\begin{aligned}
& H V=0,102 * \frac{F}{A} \approx 0,1891 * \frac{F}{d^{2}} \\
& A=\frac{d^{2}}{2 * \sin \frac{136}{2}}
\end{aligned}
$$

where F = load in Newton, $0.1891=$ Vickers constant; $\mathrm{d}=$ arithmetic mean of the two diagonals, $\mathrm{A}=$ impression surface in $\mathrm{mm}^{2}, \mathrm{HV}=$ Vickers hardness.

Each cement sample was measured at five defined points resulting in 50 measurements per cement and a total of 100 measurements. 


\section{Radiopacity}

For sample preparation stainless steel ring moulds having an internal diameter of $10.0 \mathrm{~mm}( \pm 0.1 \mathrm{~mm})$ and a height of $1.0 \mathrm{~mm}( \pm 0.1 \mathrm{~mm})$ were used according to ISO 6876:2001 [16]. Per cement ten samples were produced and allowed to set for $24 \mathrm{~h}$. From each cement one sample was placed on a dental $\mathrm{x}$-ray film (Kodak Insight Dental Film, Film Speed E, LOT 3110641, Carestream Dental, Rochester, NY, USA) together with an aluminium step wedge (1-9 mm). The $\mathrm{x}$-ray exposures were made using a Sirona Heliodent DS x-ray unit (Bensheim, Germany) with a Sirona tube and a $2.5 \mathrm{~mm}$ aluminium filter (Bensheim, Germany) added. The tube voltage was $60 \mathrm{kV}$ and the current $7 \mathrm{~mA}$. The exposure time was $120 \mathrm{~ms}$ with a constant source-to-film distance of $21 \mathrm{~cm}$. The films were developed, fixed, and dried in an automatic processor (Dürr-Dental XR 24 Nova, Dürr, Bietigheim-Bissingen, Germany).

The densities were measured with a densitometer (Darklight duo ref, Medset, Hamburg, Germany) with a measuring range $\mathrm{D}=0$ up to $\mathrm{D}>4.5$ and accuracy for $\mathrm{D}<$ $3 \pm 0.01$.

\section{Setting time}

The setting time was also evaluated according to ISO 6876:2001 [16]. The following test procedure was applied: because both cements need humidity for proper setting, a setting mould with a diameter of $10 \mathrm{~mm}$ and a height of $1 \mathrm{~mm}$ was made from dental plaster (Hinrizit, Ernst Hinrichs, Goslar, Germany). Prior to the testing of the setting time the mould was stored at $37^{\circ} \mathrm{C}$ and $95 \%$ humidity for $24 \mathrm{~h}$. Both cements were mixed according to the manufacturers' instruction and filled into the hard plaster mould. Shortly before the setting time indicated by the manufacturer an indenter point was carefully lowered onto the surface of the cement without exerting any further pressure. The indenter point had a diameter of $2( \pm 0.1) \mathrm{mm}$, a flat cylindrical end, a height of $5 \mathrm{~mm}$ and a weight of $100( \pm 5) \mathrm{g}$.

This testing was repeated every minute until on the cement surface an impression was no longer visible. The time from the end of mixing the cement until that point was recorded. For both cements the experiments were performed on six specimens each.

\section{Statistical analysis}

According to the Kolmogorov-Smirnov-test, all data were distributed normally. Thus, differences between the two cements regarding their solubility, Vickers hardness radiopacity, and setting time were analysed using the Student $t$-test at a level of significance of $p<0.05$.

\section{Results}

\section{Solubility in distilled water}

There was no change in the weight of empty moulds after immersion in water after 28 days. Both materials fulfilled the requirements of ISO 6876:2001 [16] to be less soluble than $3 \%$ after $24 \mathrm{~h}$. In the long run the weight loss after 28 days' immersion in water of Biodentine was 4.610 $( \pm 1.402) \%$ and of ProRoot MTA 1.144 $( \pm 0.328) \%$ (Table 3). At all exposure times, Biodentine was significantly more soluble than ProRoot MTA $(p<0.0001)$.

\section{Solubility in PBS buffer}

Both cements showed a different solubility in PBS buffer than in distilled water. On the surface of all specimens immersed to PBS buffer longer than $1 \mathrm{~h}$ a whitely precipitation was visible in both cements. The deposits adhered on the surfaces even after drying and were hardly to remove. The precipitation of all samples was analysed by Energy Dispersive X-ray Analysis (EDX) and imaged in a scanning electron microscope (SEM) (Figures 1 and 2). (For detailed information about this methodology see [2].) It was found that the precipitation was calcium hydroxyapatite $\left.\left(\mathrm{Ca}_{10}\left(\mathrm{PO}_{4}\right)_{6}(\mathrm{OH})_{2}\right) \times \mathrm{n} \mathrm{H}_{2} \mathrm{O}\right)$.

The solubility of Biodentine in PBS buffer was clearly lower than in distilled water, except the measured value after $24 \mathrm{~h}$. After $28 \mathrm{~d}$ even a slight increase in mass could be observed. On the contrary, for ProRoot MTA an increase in mass was detected for all test intervals, except the measured value after $10 \mathrm{~min}$. Thus, it can be concluded that ProRoot MTA is not soluble in PBS buffer. The results for both materials are shown in Table 4.

\section{Vickers microhardness}

The mean Vickers microhardness for Biodentine was with $62.35( \pm 11.55)$ HV approximately 2.5 fold higher than for ProRoot MTA with $26.93( \pm 4.66)$. The differences between Biodentine and ProRoot MTA were highly significant $(p<0.0001)$.

\section{Radiopacity}

ProRoot MTA $(6.40( \pm 0.06) \mathrm{mm} \mathrm{Al})$ was significantly more radiopaque than Biodentine $(1.50( \pm 0.10) \mathrm{mm} \mathrm{Al})$ $(p<0.0001)$. The radiopacity of Biodentine was not in accordance with ISO 6876:2001 [16].

\section{Setting time}

The final setting time was determined to be 85.66 $( \pm 6.03) \mathrm{min}$ for Biodentine and $228.33( \pm 2.88) \mathrm{min}$ for MTA. The difference was statistical highly significant $(p<0.0001)$.

\section{Discussion}

\section{Solubility in distilled water}

The solubility tests performed in the present study followed the methodology of ISO 6876:2001 [16] because Biodentine and ProRoot MTA can be used as root-end filling materials and thereby getting in direct contact with periapical tissue like sealers. 
Table 3 Solubility of Biodentine and ProRoot MTA in distilled water

\begin{tabular}{|c|c|c|c|c|c|c|c|c|c|c|c|c|}
\hline \multirow[t]{2}{*}{ Material } & \multicolumn{2}{|l|}{$1 \mathrm{~min}$} & \multicolumn{2}{|l|}{$10 \mathrm{~min}$} & \multicolumn{2}{|l|}{$1 \mathrm{~h}$} & \multicolumn{2}{|l|}{$24 \mathrm{~h}$} & \multicolumn{2}{|l|}{$72 \mathrm{~h}$} & \multicolumn{2}{|l|}{$28 d$} \\
\hline & Mean & (SD) & Mean & (SD) & Mean & (SD) & Mean & (SD) & Mean & (SD) & Mean & (SD) \\
\hline Biodentine & 0.252 & $(0.100)$ & 0.999 & $(0.202)$ & 1.437 & $(0.426)$ & 2.647 & $(0.583)$ & 3.700 & $(0.782)$ & 4.610 & $(1.402)$ \\
\hline ProRoot MTA & 0.026 & $(0.017)$ & 0.247 & $(0.114)$ & 0.763 & $(0.235)$ & 0.880 & $(0.237)$ & 0.940 & $(0.516)$ & 1.144 & $(0.328)$ \\
\hline$p$-value & $<0.0001$ & & $<0.0001$ & & $<0.0001$ & & $<0.0001$ & & $<0.0001$ & & $<0.0001$ & \\
\hline
\end{tabular}

Given are the mean percentages with SD of weight loss for each material and for each immersion period. The differences were significantly different $(p<0.0001 ; t$-test).

However, while weight loss of the test specimens was recorded by determining the decline in mass of the material samples after storage in water, as already described by some authors [28-31], the International Standard suggests that the increase in weight of the dish in which the samples have been placed (residue method) should be ascertained as the amount of material removed from the specimens [16,32,33]. The specimens were weighed in order to avoid an underestimation of the material going into solution. In order to enhance the accuracy of the measurements, one sample was used for just one immersion period, thus undesirable weight loss of the cements due to repeated drying and immersion was excluded.

It has to be kept in mind that with regard to the strict definition of the physicochemical term solubility, the test used in the present study measured the elution of watersoluble material, but not the solubility. Solubility of a solid is the situation where a pure chemical compound is in thermodynamic equilibrium with its solution [34]. Moreover, it has to be taken into account, that measuring weight differences of the cement specimens may also record disintegration processes that may not be the result of dissolution. For instance, particles of the material may fall out from the cement structure during storage in the liquid [29,34]. Furthermore, water uptake may compensate



Figure 1 SEM micrograph of the whitish precipitate on the Biodentine surface after $28 \mathrm{~d}$ storage in PBS buffer. The form of a lotus flower blossom was described earlier [43]. Original magnification $\times 6400$. The distance between the white bars represents $10 \mu \mathrm{m}$. for dissolved material $[29,30,35]$. Hence, it can be discussed if a solubility test in distilled water is of clinical relevance. Nevertheless, it was found that both materials fulfilled the requirements of ISO 6876:2001 [16] and showed a solubility of $<3 \%$ after $24 \mathrm{~h}$. Biodentine was significant more soluble than ProRoot MTA at all time periods. Under the conditions of this in vitro study ProRoot MTA can be described as nearly insoluble. This finding is in accordance with other reports [15,36-38].

On the other hand it must bear in mind that cements like MTA or Biodentine forming calcium hydroxide or calcium oxide during setting should present a certain degree of solubility to improve the mineralization process in contact with vital tissue. $\mathrm{OH}^{-}$and $\mathrm{Ca}^{2+}$ release is necessary and related to the solubility of the cements. The alkaline $\mathrm{pH}$ and calcium release is linked with the ability to stimulate mineralization. It was shown that materials more soluble than MTA had higher $\mathrm{OH}^{-}$and $\mathrm{Ca}^{2+}$ release [39].

\section{Solubility in PBS buffer}

In addition to the solubility test in distilled water, in the present study the solubility of Biodentine and ProRoot MTA was also evaluated in PBS buffer. This was assessed for a better understanding of the advantages of bioactive components to be released from calcium

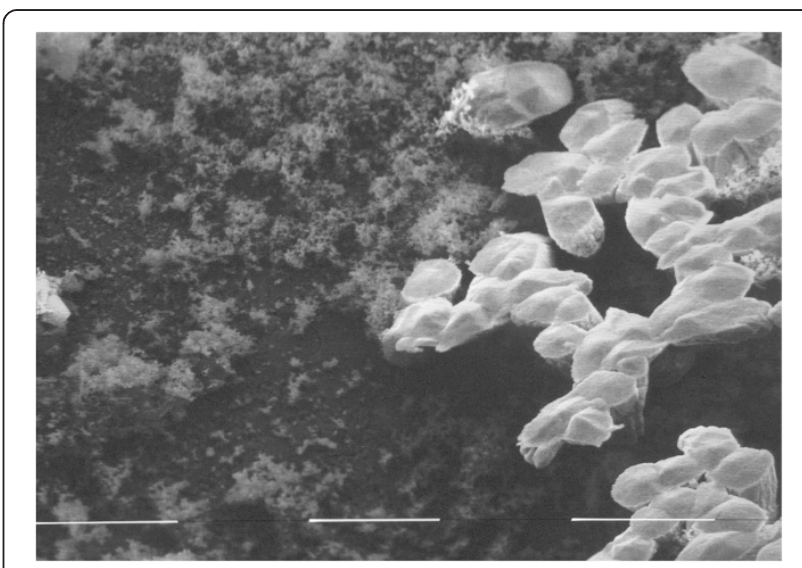

Figure 2 SEM micrograph of the whitish precipitate on the MTA surface after $28 \mathrm{~d}$ storage in PBS buffer. The precipitates were more peltiform and thus different from the Biodentine samples. Original magnification $\times$ 6400. The distance between the white bars represents $10 \mu \mathrm{m}$. 
Table 4 Solubility of Biodentine and ProRoot MTA in PBS buffer

\begin{tabular}{|c|c|c|c|c|c|c|c|c|c|c|c|c|}
\hline \multirow[t]{2}{*}{ Material } & \multicolumn{2}{|l|}{$1 \mathrm{~min}$} & \multicolumn{2}{|l|}{$10 \mathrm{~min}$} & \multicolumn{2}{|l|}{$1 \mathrm{~h}$} & \multicolumn{2}{|l|}{$24 \mathrm{~h}$} & \multicolumn{2}{|l|}{$72 \mathrm{~h}$} & \multicolumn{2}{|l|}{$28 \mathrm{~d}$} \\
\hline & Mean & (SD) & Mean & (SD) & Mean & (SD) & Mean & (SD) & Mean & (SD) & Mean & (SD) \\
\hline Biodentine & 0.162 & $(0.170)$ & 0.253 & $(0.144)$ & 1.367 & $(0.264)$ & 3.415 & $(0.684)$ & 3.274 & $(1.075)$ & -0.053 & $(0.669)$ \\
\hline ProRoot MTA & -0.029 & $(0.222)$ & 0.077 & $(0.074)$ & -0.688 & (0.098) & -2.871 & $(0.256)$ & -5.187 & (1.019) & -5.383 & $(0.501)$ \\
\hline$p$-value & $<0.0001$ & & $<0.0001$ & & $<0.0001$ & & $<0.0001$ & & $<0.0001$ & & $<0.0001$ & \\
\hline
\end{tabular}

Given are the mean percentages with SD of weight loss for each material and for each immersion period. The differences were significantly different $(p<0.0001$; $t$-test). Negative values mean an increase in weight.

silicate cements [40]. From other studies it is known that these cements have the ability to form hydroxyapatite crystals on their surface after contact with phosphate containing liquids like body fluid or PBS buffer [17-19]. Calcium ions, the dominant ion released from calcium silicate cements, may react with the phosphate in the PBS buffer to hydroxyapatite [17]. In the present study, this could be confirmed for MTA as well as for Biodentine.

The negative values given in Table 4 mean an increase in weight. Thus, it may be concluded that nearly all MTA samples absorbed mass from the PBS buffer. In the Biodentine group this was only observed after $28 \mathrm{~d}$. It may be speculated that Biodentine may release a higher amount of calcium ions in the PBS buffer which may explain the higher solubility in contrast to MTA. In other studies Biodentine showed a higher level of calcium ion release than MTA after storage in Hank's Balanced Salt Solution (HBSS) and PBS buffer, respectively $[41,42]$. This may explain the present results.

The SEM micrographs showed the pattern of crystallization of Biodentine, which resembles a lotus flower blossom (Figure 1) as described earlier [43]. In contrast the precipitates found on the MTA samples are more peltiform (Figure 2). The reason for the different crystallization forms is unknown yet. Thus, further research to analyse the exact chemical composition of the white precipitate and to evaluate the increase in weight after storage in PBS buffer is under preparation.

\section{Vickers microhardness}

The measurement of the Vickers microhardness was undertaken with $5 \mathrm{~mm}$ thick samples to simulate clinical application. Matt et al. recommended $5 \mathrm{~mm}$ thick ProRoot MTA as an apical barrier, which was significantly harder than a barrier of $2 \mathrm{~mm}$ [44]. In addition the minimal thickness for ProRoot MTA given in the literature as root-end filling material is $3 \mathrm{~mm}$ [45] and for apical plug formation $4 \mathrm{~mm}$ [46].

Regarding Vickers microhardness, it was found that Biodentine was significantly harder than ProRoot MTA. In the present study, the Vickers microhardness for ProRoot MTA was quite low compared with that derived from other publications where the microhardness of ProRoot MTA was found to be between about $40 \mathrm{HV}$ and $60 \mathrm{HV}$ [36,47-51]. This can be related to different experimental setups.

The Vickers microhardness for Biodentine was about $62 \mathrm{HV}$ after one day which is in accordance with the results of Pradelle-Plasse et al. [52] who reported values between $51 \mathrm{HV}$ after $2 \mathrm{~h}$ and $69 \mathrm{HV}$ after 1 month.

Camilleri found a Vickers microhardness of even about $130 \mathrm{HV}$ which decreased to about $90 \mathrm{HV}$ after $1 \mathrm{~min}$ etching with $35 \%$ phosphoric acid [53], whereas in a recent publication a Vickers microhardness of $48.4 \mathrm{HV}$ after $28 \mathrm{~d}$ immersion in Hank's balanced salt solution (HBSS) was reported [54]. These slightly lower values may be related to the storage in HBSS.

Nevertheless, the Vickers microhardness of sound human dentine is about $60 \mathrm{HV}$ and $90 \mathrm{HV}$ [20-22] and thus approximately identical to Biodentine but more than 2-fold higher than that of ProRoot MTA as found in this study. It can be concluded that Biodentine may have a mechanical behaviour similar to human dentine whereas ProRoot MTA seams to be unsuitable for longterm clinical use as a restorative base or to replace dentine. Under this aspect, Biodentine may be used as a dentine substitute.

\section{Radiopacity}

According to the present results, ProRoot MTA was significantly more radiopaque than Biodentine. The radioopacity of ProRoot MTA was found to be $6.5 \mathrm{~mm} \mathrm{Al}$, which is in accordance with the current literature [15,36,55-60].

The radioopacity value of Biodentine was found to be $1.5 \mathrm{~mm} \mathrm{Al}$ thickness. This is in contrast to the manufacturer's information who claimed that Biodentine possess a radiopacity of $3.5 \mathrm{~mm} \mathrm{Al}$ and also in contract to the results of a study by Grech et al. in which Biodentine displayed a radiopacity of 3.3 to $4.1 \mathrm{~mm} \mathrm{Al}$ after immersion in HBSS for $1 \mathrm{~d}$ and $28 \mathrm{~d}$, respectively [54]. In a recent study values of $2.8 \pm 0.48 \mathrm{~mm}$ Al were reported [61]. Thus, the wide range of radiopacities values of Biodentine as given so far in the literature (2.8 to $4.1 \mathrm{~mm} \mathrm{Al}$ ) together with the finding of the present study may indicate a certain lack of product standardisation. Certainly, additional investigation are warranted to further elucidate the discrepancy in the values given by the manufacturer or by other authors $[54,61]$ and the 
results of the present study, yet. However, in contrast to ProRoot MTA Biodentine is hardly to distinguish from dentine radiographically, which may support the present results.

The difference in radiopacity between Biodentine and ProRoot MTA may be explained by the use of different radiopacifieres. Whereas ProRoot MTA contains about 2 at\% bismuth [1,2], $5 \%$ of zirconium oxide $\left(\mathrm{ZrO}_{2}\right)$ is added to Biodentine as radiopacifier (according to manufacturer's information). Under the aspect of biocompatibility zirconium oxide seems to be superior compared to bismuth oxide [60], but obviously the amount seems to be insufficient in Biodentine. A radiopacity value of about $1.5 \mathrm{~mm}$ $\mathrm{Al}$ for Biodentine is too low for clinical use and should thus be improved.

\section{Setting time}

The initial setting time according to the manufacturer of Biodentine is about $12 \mathrm{~min}$. In the present study, the final setting time of Biodentine was $85.66( \pm 6.03) \mathrm{min}$ and thus sevenfold longer. Grech et al. evaluated the setting time of Biodentine to be $45 \mathrm{~min}$ according to ISO 9917-1:2007 [54]. The difference in the determined setting time may be explained by the different ISO standards used. Nevertheless, in both studies the setting time for Biodentine was significantly longer than the initial setting time given in the instructions of the manufacturer and should be taken into consideration when using this cement.

In the present study, the setting time of MTA was $228.33( \pm 2.88) \mathrm{min}$, whereas other studies reported setting times for ProRoot MTA between $165( \pm 5) \mathrm{min}$ [15] and $170( \pm 2) \mathrm{min}$ [62]. Nevertheless, the setting time for ProRoot MTA was significant longer than for Biodentine, which may be a disadvantage in clinical practice.

\section{Conclusion}

The null hypothesis of this study has to be rejected as Biodentine and ProRoot MTA showed marked differences in their physicochemical properties. Concerning solubility, both materials fulfilled the requirements of ISO 6876:2001 [16] but Biodentine was significantly more soluble than ProRoot MTA. The increased solubility may be an advantage in regard to bioactivity, but further research is necessary. Biodentine possess a significantly higher Vickers microhardness compared to ProRoot MTA. Hence, concerning surface hardness this cement may be denoted as a dentine substitute. The radioopacity value of Biodentine was significantly lower than that of ProRoot MTA and not in accordance with ISO 6876 [16]. The radiodensity of Biodentine should be improved. The setting time of Biodentine is significantly lower than that of ProRoot MTA, which may be an advantage in clinical practice.

\section{Abbreviations}

$\mathrm{Ca}(\mathrm{OH})_{2}$ : Calcium hydroxide; EDX: Energy Dispersive X-ray Analysis; HBSS: Hank's balanced salt solution; HV: Vickers microhardness; ISO: International standard organisation; MTA: Mineral trioxide aggregate; PBS: Phosphate buffered saline; SEM: Scanning electron microscope.

\section{Competing interests}

The authors declare that they have no competing interests.

\section{Authors' contributions}

All authors have contributed significantly to this work and contributed to the paper in the equal parts: MK had the idea for the research and developed the concept, performed the in vitro experiments, participated in literature research and carried out proofreading. ES participated in the design of the study, in literature research, writing of the manuscript, performed the statistical analysis and carried out proofreading. TD participated in study development, material testing, literature research, writing of the manuscript and carried out proofreading. All authors read and approved the final manuscript. All authors are in agreement with the content of the manuscript.

\section{Acknowledgments}

We are grateful to Priv.-Doz. Dr. Gunther Brunklaus, Institute for Physical Chemistry, Westphalian Wilhelms-University, Münster, Germany for kindly analyzing the whitely precipitation of ProRoot MTA and Biodentine after storage in PBS buffer by Energy Dispersive X-ray Analysis (EDX).

\section{Author details}

'Department of Operative Dentistry, Westphalian Wilhelms-University, Albert-Schweitzer-Campus 1, building W 30, 48149 Münster, Germany. ${ }^{2}$ Central Interdisciplinary Ambulance in the School of Dentistry, Albert-Schweitzer-Campus 1, building W 30, 48149 Münster, Germany.

Received: 2 February 2015 Accepted: 24 April 2015

Published online: 02 May 2015

\section{References}

1. Camilleri J, Montesin FE, Brady K, Sweeney R, Curtis RV, Pitt Ford TR. The constitution of mineral trioxide aggregate. Dent Mater. 2005;21:297-303.

2. Dammaschke T, Gerth HUV, Züchner H, Schäfer E. Chemical and physical surface and bulk material characterization of white ProRoot MTA and two Portland cements. Dent Mater. 2005;21:731-8.

3. Holland R, de Souza V, Nery MJ, Otoboni Filho JA, Bernabé PFE, Dezan JE. Reaction of dogs' teeth to root canal filling with mineral trioxide aggregate or a glass ionomer sealer. J Endod. 1999:25:728-30.

4. Faraco Júnior IM, Holland R. Response of the pulp of dogs to capping with mineral trioxide aggregate or a calcium hydroxide cement. Dent Traumatol. 2001;17:163-6.

5. Takita T, Hayashi M, Takeichi O, Ogiso B, Suzuki N, Otsuka K, et al. Effect of mineral trioxide aggregate on proliferation of cultured human dental pulp cells. Int Endod J. 2006;39:415-22.

6. Parirokh M, Torabinejad M. Mineral trioxide aggregate: a comprehensive literature review - Part I: chemical, physical, and antibacterial properties. J Endod. 2010;36:16-27.

7. Torabinejad M, Parirokh M. Mineral trioxide aggregate: a comprehensive literature review - Part II: leakage and biocompatibility investigations. J Endod. 2010;36:190-202.

8. Parirokh M, Torabinejad M. Mineral trioxide aggregate: a comprehensive literature review - Part III: Clinical applications, drawbacks, and mechanism of action. J Endod. 2010;36:400-13.

9. Karabucak B, Li D, Lim J, lqbal M. Vital pulp therapy with mineral trioxide aggregate. Dent Traumatol. 2005;21:240-3

10. Stropko JJ. Micro-surgical endodontics. In: Castellucci A, editor. Endodontics, vol. III. Florence: Edizioni Odontoiatriche II Tridente; 2009. p. 1118-25.

11. Belobrov I, Parashos P. Treatment of tooth discoloration after the use of white mineral trioxide aggregate. J Endod. 2011;37:1017-20.

12. Dammaschke T. Direct pulp capping. Dentist. 2011;27(8):88-94.

13. Gutmann $J L$, Lovedahl PE. Problem-solving challenges in periapical surgery. In: Gutmann JL, Lovedahl PE, editors. Problem solving in endodontics. 5th ed. Maryland Heights: Elsevier Mosby; 2011. p. 351. 
14. Laurent P, Camps J, de Méo M, Déjou J, About I. Induction of specific cell responses to a $\mathrm{Ca}_{3} \mathrm{SiO}_{5}$-based posterior restorative material. Dent Mater. 2008;24:1486-94.

15. Torabinejad M, Hong CU, McDonald F, Pitt Ford TR. Physical and chemical properties of a new root-end filling material. J Endod. 1995;21:349-53.

16. International Organization for Standardization. International Standard ISO 6876:2001: Dental root canal sealing materials. Geneva: International Organization for Standardization; 2001

17. Sarkar NK, Caicedo R, Ritwik P, Moiseyeva R, Kawashima I. Physicochemical basis of the biologic properties of mineral trioxide aggregate. J Endod. 2005;31:97-100.

18. Asgary S, Eghbal MJ, Parirokh M, Ghoddusi J. Effect of two storage solutions on surface topography of two root-end filling. Aust Endod J. 2008;35:147-52.

19. Gandolfi MG, van Lunduyt K, Taddei P, Modena E, van Meerbeek B, Prati C. Environmental scanning electron microscopy connected with energy dispersive $X$-ray analysis and Raman techniques to study ProRoot Minera Trioxide Aggregate and calcium silicate cements in wet conditions and in real time. J Endod. 2010;36:851-7.

20. Ryge G, Foley DE, Fairhurst CW. Microindentation hardness. J Dent Res. 1961;40:1116-26

21. Fuentes V, Toledano M, Osorio R, Carvalho RM. Microhardness of superficial and deep sound human dentin. J Biomed Mater Res A. 2003;66A:850-3.

22. Lai YL, Yang ML, Lee SY. Microhardness and color changes of human dentin with repeated intracoronal bleaching. Oper Dent. 2003;28:786-92.

23. Manson-Hing LR. An investigation of the roentgenographic contrast of enamel, dentine and aluminium. Oral Surg Oral Med Oral Pathol. 1961;14:1456-72.

24. Vivan RR, Ordinola-Zapata R, Bramante CM, Bernardineli N, Garcia RB, Hungaro Duarte MA, et al. Evaluation of the radiopacity of some commercial and experimental root-end filling material. Oral Surg Oral Med Oral Pathol Oral Radiol Endod. 2009;108:e35-8.

25. Shah PMM, Chong BS, Sidhu SK, Pitt Ford TR. Radiopacity of potential root-end filling materials. Oral Surg Oral Med Oral Pathol Oral Radiol Endod. 1996;81:476-9.

26. Persson C, Engqvist H. Premixed calcium silicate cement for endodontic applications: injectability, setting time and radioopacity. Biomatter. 2011;1:76-80.

27. Santos AD, Araujo EB, Yukimitu K, Barbosa JC, Moraes JC. Setting time and thermal expansion of two endodontic cements. Oral Surg Oral Med Oral Pathol Oral Radiol Endod. 2008;106:e77-9.

28. McComb D, Smith DC. Comparison of physical properties of polycarboxylatebased and conventional root canal sealers. J Endod. 1976;2:228-35.

29. Ørstavik D. Weight loss of endodontic sealers, cements and pastes in water. Scand J Dent Res. 1983;91:316-9.

30. Kazemi RB, Safavi KE, Spångberg LSW. Dimensional changes of endodontic sealers. Oral Surg Oral Med Oral Pathol. 1993;76:766-71.

31. Ono K, Matsumoto K. Physical properties of $\mathrm{CH} 61$, a newly developed root canal sealer. J Endod. 1998;24:244-7.

32. Higginbotham TL. A comparative study of the physical properties of five commonly used root canal sealers. Oral Surg Oral Med Oral Pathol. 1967:24:89-101.

33. Kaplan AE, Goldberg F, Artaza LP, De Silvio A, Macchi RL. Disintegration of endodontic cements in water. J Endod. 1997:23:439-41.

34. Wilson AD. Specification test for the solubility and disintegration of dental cements: A critical evaluation of its meaning. J Dent Res. 1976;55:721-9.

35. Caicedo R, von Fraunhofer JA. The properties of endodontic sealer cements. J Endod. 1988;14:527-34.

36. Danesh G, Dammaschke T, Gerth HUV, Zandbiglari T, Schäfer E. A comparative study of selected properties of ProRoot MTA and two Portland cements. Int Endod J. 2006;39:213-9.

37. Poggio C, Lombardini M, Alessandro C, Simonetta R. Solubility of root-endfilling materials: a comparative study. J Endod. 2007;33:1094-7.

38. Shie MY, Huang TH, Kao CT, Huang CH, Ding SJ. The effect of a physiologic solution $\mathrm{pH}$ on properties of white mineral trioxide aggregate. J Endod. 2009;35:98-101.

39. Vivan RR, Ordinola-Zapata R, Zeferino MA, Bramante CM, Bernardineli N, Garcia RB, et al. Evaluation of the physical and chemical properties of two commercial and three experimental root-end filling material. Oral Surg Oral Med Oral Pathol Oral Radiol Endod. 2010;110:250-6.

40. Borges RP, Sousa-Neto MD, Varsiani MA, Rached-Júnior FA, De-Deus G, Miranda CES, et al. Changes in the surface of four calcium silicatecontaining endodontic materials and an epoxy resin-based sealer after a solubility test. Int Endod J. 2012;45:419-28.
41. Grech L, Mallia B, Camilleri J. Characterization of set Intermediate Restorative Material, Biodentine, Bioaggregate and prototype calcium silicate cement for use as root-end filling materials. Int Endod J. 2013;46:632-41.

42. Han L, Okiji T. Bioactivity evaluation of three calcium silicate-based endodontic materials. Int Endod J. 2013;46:808-14.

43. Gjorgievska ES, Nicholson JW, Apostolska SM, Coleman NJ, Booth SE, Slipper IJ, et al. Interfacial properties of three different bioactive dentine substitutes. Microsc Microanal. 2013;19:1450-7.

44. Matt GD, Thorpe JR, Strother JM, McClanahan SB. Comparative study of white and gray mineral trioxide aggregate (MTA) simulating a one- or two-step apical barrier technique. J Endod. 2004;30:876-9.

45. Lamb EL, Loushine RJ, Weller RN, Kimbrough WF, Pashley DH. Effect of root resection on the apical sealing ability of mineral trioxide aggregate. Oral Surg Oral Med Oral Pathol Oral Radiol Endod. 2003;95:732-5.

46. Giuliani V, Baccetti T, Pace R, Pagavino G. The use of MTA in teeth with necrotic pulps and open apices. Dent Traumatol. 2002;18:217-21.

47. Nekoofar MH, Adusei G, Sheykhrezae MS, Hayes SJ, Bryant ST, Dummer $\mathrm{PMH}$. The effect of condensation pressure on selected physical properties of mineral trioxide aggregate. Int Endod J. 2007;40:453-61.

48. Namazikhah MS, Nekoofra MH, Sheykhrezae MS, Salariyeh S, Hayes SJ, Bryant ST, et al. The effect of pH on the surface hardness and microstructure of mineral trioxide aggregate. Int Endod J. 2008;41:108-16.

49. Nekoofar MH, Aseeley Z, Dummer PMH. The effect of various mixing techniques on the surface microhardness of mineral trioxide aggregate. Int Endod J. 2010;43:312-20.

50. Nekoofar MH, Oloomi K, Sheykhrezae MS, Tabor R, Stone DF, Dummer PMH. An evaluation of the effect of blood and human serum on the surface microhardness and surface microstructure of mineral trioxide aggregate. Int Endod J. 2010;43:849-58.

51. Kang JS, Rhim EM, Huh SY, Ahn SJ, Kim DS, Kim SY, et al. The effects of humidity and serum on the surface microhardness and morphology of five retrograde filling materials. Scanning. 2012;34:207-14.

52. Pradelle-Plasse N, Tran X-V, Colon P. Physico-chemical properties. In: Goldberg M, editor. Biocompatibility or cytotoxic effects of dental composites. Oxford: Coxmoor; 2009. p. 184-94.

53. Camilleri J. Investigation of Biodentine as dentine replacement material. J Dent. 2013;41:600-10.

54. Grech L, Mallia B, Camilleri J. Investigation of the physical properties of tricalcium silicate cement-based root-end filling materials. Dent Mater. 2013;29:e20-8.

55. Laghios CD, Benson BW, Gutmann JL, Cutler CW. Comparative radiopacity of tetracalcium phosphate and other root-end filling materials. Int Endod J. 2000;33:311-5.

56. Chng HK, Islam I, Yap AUJ, Tong YW, Koh ET. Properties of a new root-end filling material. J Endod. 2005;31:665-8.

57. Islam I, Chng HK, Yap AU. Comparison of the physical and mechanical properties of MTA and Portland cement. J Endod. 2006;32:193-7.

58. Kim EC, Lee BC, Chang HS, Lee W, Hong CU, Min KS. Evaluation of the radiopacity and cytotoxicity of Portland cements containing bismuth oxide. Oral Surg Oral Med Oral Pathol Oral Radiol Endod. 2008;105:54-7.

59. Camilleri J, Gandolfi MG. Evaluation of the radiopacity of calcium silicate cements containing different radiopacifiers. Int Endod J. 2010;43:21-30.

60. Cutajar A, Mallia B, Abela S, Camilleri J. Replacement of radiopacifier in mineral trioxide aggregate; characterization and determination of physical properties. Dent Mater. 2011;27:879-91.

61. Tanalp J, Karapınar-Kazandağ M, Dölekoğlü S, Kayahan MB. Comparison of the radiopacities of different root-end filling and repair materials. ScientificWorldJournal. 2013;594950.

62. Gandolfi MG, lacono F, Agee K, Siboni F, Tay F, Pashley DH, et al. Setting time and expansion in different soaking media of experimental accelerated calcium-silicate cements and ProRoot MTA. Oral Surg Oral Med Oral Pathol Oral Radiol Endod. 2009;108:e39-45.

63. Berzins DW. Chemical properties of MTA. In: Torabinejad M, editor. Minera Trioxide Aggregate. Properties and clinical applications. Ames: Wiley Blackwell; 2014. p. 17-35. 